\title{
SIMULATED PILOT-IN-THE-LOOP TESTING OF HANDLING QUALITIES OF THE FLEXIBLE WING AIRCRAFT
}

\author{
Vilius PORTAPAS (D) ${ }^{1, *}$, Alastair COOKE (D) ${ }^{2}$ \\ ${ }^{1}$ Department of Engineering Design and Mathematics, University of the West of England, Bristol, United Kingdom \\ ${ }^{2}$ Centre for Aeronautics, Cranfield University, Cranfield, United Kingdom
}

Received 20 November 2019; accepted 09 February 2020

\begin{abstract}
This article aims to indicate the differences between rigid and flexible wing aircraft flying (FQ) and handling (HQ) qualities. The Simulation Framework for Flexible Aircraft was used to provide a generic cockpit environment and a piloted mathematical model of a bare airframe generic high aspect ratio wing aircraft (GA) model. Three highly qualified test pilots participated in the piloted simulation trials campaign and flew the GA model with both rigid and flexible wing configurations. The results showed a negligible difference for the longitudinal HQs between rigid and flexible wing aircraft. However, significant changes were indicated for the lateral/directional HQs of the flexible wing aircraft. A wing ratcheting phenomenon manifested itself during the roll mode tests, the spiral mode exhibited neutral stability and the Dutch roll mode shape changed from a horizontal to a vertical ellipse. The slalom task flight tests, performed to assess the FQs of the aircraft, revealed the degradation of both the longitudinal and lateral/directional FQs.
\end{abstract}

Keywords: aeroelasticity, flexible aircraft, flight dynamics, handling qualities, piloted simulation trials.

\section{Introduction}

Over the last few decades society has witnessed significant achievements in aviation. Air travel has become so affordable that the number of passengers is expected to double in the next 20 years and airlines keep introducing longer revenue flights, which range for about $15000 \mathrm{~km}$ and last for more than 17 hours, to connect the most distant places of our planet. Economic and social benefits that the aviation industry induces globally are greatly appreciated and understood (Anonymous, 2017; ATAG, 2016). However, they come at a cost of a negative environmental impact, for which the aviation sector is highly criticised. To reduce this impact, international aviation organizations such as the International Civil Aviation Organization (ICAO), the International Air Transport Association (IATA) and the European Civil Aviation Conference (ECAC) set environmental targets to significantly reduce emissions (IATA, 2013; Tollefson, 2016) that can be achieved only by improving aircraft efficiency. One of the potential improvements is to increase the wing aspect ratio (AR) to reduce the induced drag. High AR unswept wings are usually seen in sailplane designs to provide very high lift-to-drag ratios, but could not be used for large transport aircraft in the past because of arising structural issues due to the much higher wing loading when compared to sailplanes. With the advent of composite materials and novel manufacturing technologies (Kellari, Crawley, \& Cameron, 2018), previous structural issues have been solved. As AR increases, larger wing bending deformations develop. Thus, understanding their effect on flying (FQ) and handling (HQ) qualities is vital, as they will affect design considerations of airframes and flight control systems (FCS).

Previous approaches to assess HQs of flexible aircraft were mainly based on the longitudinal dynamics (Andrews, 2011; Damveld, 2009; Field \& Rossitto, 1999; Waszak \& Schmidt, 1988). As pilots, placed in front of an aircraft, experienced different dynamics than the ones at the centre of gravity (CG) due to the bending of long slender fuselages, it was important to investigate the way those deformations altered pilots' perception of HQs. One of such assessments was done by Waszak, Davidson, and Schmidt (1987) at the NASA Langley Visual/Motion Simulator facility for the Rockwell B-1 aircraft. Based on this research Damveld (2009) developed a new method to investigate and quantify the longitudinal HQs - experimental behaviour measurement method. Andrews (2011), on the other hand, investigated the impact of both the fuselage and the wing flexibility on HQs of a large commercial

*Corresponding author. E-mail: vilius.portapas@uwe.ac.uk 
transport aircraft. He also developed the AX-1 model the foundational part of the Cranfield Accelerated Aircraft Loads Model $\left(\mathrm{CA}^{2} \mathrm{LM}\right)$ framework used for the modelling and simulation activities described in this paper. However, the commercial aircraft that Andrews investigated possessed a relatively rigid wing - a feature of large commercial aircraft until the Boeing 787 (Dodt, 2011) and Airbus A350 were introduced. As large aircraft were fitted with relatively rigid wings, the unmanned aerial vehicles (UAV) served as test beds for high AR wing (HARW) technologies. Much effort was made in the USA to develop methodologies and technologies to both manufacture and investigate HARW UAVs. The Helios Prototype (Noll et al., 2004) is the most famous example of HARW UAV. Helios is also a well-known example of the in-flight structural disintegration due to high wing deformations. As the manufacturing technologies advanced, the researchers started to look into HARW applicability to large commercial aircraft. The Subsonic Ultra Green Aircraft Research, initiated by Boeing and NASA, is a well-known investigation into the applicability of high AR low swept wings for commercial aircraft (Bradley, Droney, \& Allen, 2015). Airbus along with its academic partners Cranfield University and the University of Bristol proposed the High Aspect Ratio Technology ENabler (Cooper et al., 2014). Both concepts consider HARW as well as many other novel technologies designed to enable improvements in aircraft efficiency.

These new HARW concepts not only increase aircraft efficiency, but also introduce new aircraft dynamics. As the structural issues of HARW were analysed in the Helios report (Noll et al., 2004), the FQs and HQs of such aircraft have never been assessed before. Hence, piloted simulation trials were carried out during the research activities described in this article to compare the differences of FQs and HQs between relatively rigid and highly flexible wing aircraft through a set of standard flight test manoeuvres and a recently developed slalom task. The Simulation Framework for Flexible Aircraft (SFFA) was developed to perform the trials. Moreover, the opinions collected from professional test pilots, who participated in the simulation campaign, allowed an assessment of both FQs and HQs of a generic HARW aircraft model (GA).

This article reveals significant changes in the lateral/ directional dynamics between rigid and flexible wing aircraft configurations. It also proves the suitability of the SFFA to be used as a pilot-in-the-loop testing tool of new aircraft configurations. Lastly, it proves the suitability of the slalom task as a rapid flight testing technique that is capable to reveal the deficiencies in FQs and HQs of new aircraft designs.

This article consists of two sections. Section 1 briefly reviews SFFA, the experience of test pilots, who participated in the simulation campaign, and defines the GA model along with the flight test manoeuvres used for the piloted simulation trials campaign. Section 2 reviews the results for both longitudinal and lateral/directional HQs as well as the results from the slalom task simulations used to assess FQs.

\section{Methodology}

The simulation campaign was carried out using the newly developed SFFA at the Aerospace Integration Research Centre at Cranfield University. Three certified test pilots flew flexible and rigid wing configurations of the GA model through a series of flight test manoeuvres to induce longitudinal and lateral/directional modes. These piloted simulation trials allowed to assess HQs of aircraft configurations. Pilots also assessed FQs during the slalom task with respect to the Cooper-Harper Rating (CHR) scale

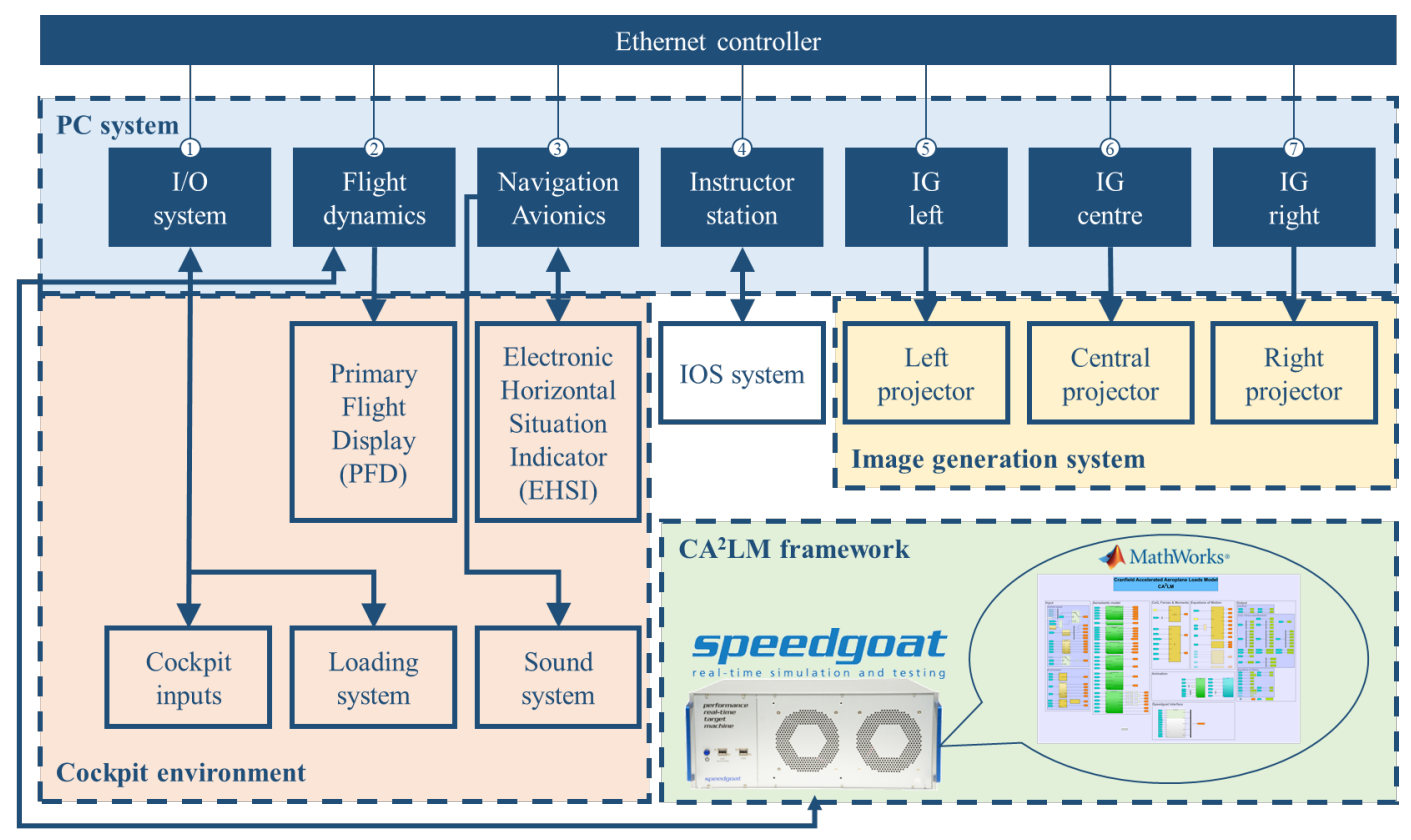

Figure 1. The architecture of SFFA 
(Cooper \& Harper, 1969). Comparison of the dynamics of flexible and rigid wing GA allowed identification of the differences between the two configurations.

\subsection{Simulation framework for flexible aircraft}

SFFA consists of three main components, which are the $\mathrm{CA}^{2} \mathrm{LM}$ framework, the engineering flight simulator EFS500 and the Speedgoat real-time target machine that connects the previous two components. Figure 1 shows the overall architecture of SFFA.

The CA ${ }^{2}$ LM framework (Dussart et al., 2018; Portapas, Cooke, \& Lone, 2016) provides an environment for the aeroservoelastic modelling of flexible aircraft. The Leishman $(1988,1993,1994)$ unsteady aerodynamics model that makes use of Theodorsen (1949) and Wagner (1925) functions along with the Modified Strip Theory (DeLaurier, 1993) defines aerodynamics of the wing, horizontal (HTP) and vertical (VTP) tailplanes. Such a modelling approach combines the capability of real-time pilot-in-the-loop simulations, whilst capturing the aerodynamic effects necessary for the aeroservoelastic analysis of an aircraft (Kim et al., 2008). For the current test case NASA SC(2)-0610 aerofoil was used to model aerodynamics of the wing and NASA SC(2)-0010 aerofoil to model aerodynamics of HTP and VTP. Fuselage flexibility effects are divided into two parts and its forebody is modelled as a slender axisymmetric forebody-cylinder combination (ESDU, 1990, 2004), while the aftbody is modelled as a conical boat-tail (ESDU, 1992). Engine nacelles are modelled as annular aerofoils (ESDU, 2013). Once calculated the aerodynamic loading is then transferred to the structural frame to get the airframe deformations. The structural dynamics in the $\mathrm{CA}^{2} \mathrm{LM}$ framework use the modal form, which means that the overall deformation of the structure depends on the sum of the modeshapes, and is the implementation of the linear structural dynamics model. Widely accepted opinion states that wingtip deflections of less than $10 \%$ of semi-span can be treated as linear deformations. However, large wing deformations are of interest in this research and a nonlinear structural model should be used instead. Nonetheless, Patil and Hodges (2004) showed that the linear structural model predicts deformations with similar accuracy as the nonlinear structural model for the static wingtip deflections of around 25\% semi-span. However, for the dynamic loading case the linear structural model could not capture same dynamics as the nonlinear one (Patil \& Hodges, 2004). Due to this limitation current version of the $\mathrm{CA}^{2} \mathrm{LM}$ framework could only be used for investigations of low frequency phenomena. Hence, the assumption of low frequency wing deformations was made.

The EFS500 flight simulator provides a cockpit environment and an image generation capability enabling pilot-in-the-loop simulations. Although EFS500 was described previously by Lopez Matos et al. (2018), the struc- ture of the simulator is briefly covered here. The EFS500 flight simulator consists of the following components (Allerton, 2016):

1. Input/output system is based on the Raspberry $\mathrm{Pi}$ platform and performs an analogue-digital signal conversion and broadcasts between the computer system and the inceptors.

2. Flight dynamics computer calculates the state and position parameters of a simulated aircraft. However, for the current case, the $\mathrm{CA}^{2} \mathrm{LM}$ framework overwrote its calculations to allow flexible wing aircraft simulations, but the computer still provided the primary flight display.

3. Cockpit environment provides a generic single seat cockpit layout with a sidestick, rudder pedals and throttle lever. Basic pilot instruments, i.e. the primary flight display and the electronic horizontal situation indicator, are also provided.

4. Artificial loading system provides force feedback to the rudder pedals.

5. Computer system of six PC stations provides cockpit displays, avionics, instructor operating system and image generation capabilities.

6. Sound generation system generates environment and warning sounds.

7. Image generation system consists of three projectors and a spherical $140^{\circ}$ by $40^{\circ}$ field-of-view screen.

All computers are connected into a local network by a 16-channel Ethernet switch and run at the frequency of $50 \mathrm{~Hz}$.

The Speedgoat real-time target machine - another essential component of the system - speeds up the $\mathrm{CA}^{2} \mathrm{LM}$ framework and provides an interface between the framework and the EFS500 flight simulator. The $\mathrm{CA}^{2} \mathrm{LM}$ framework is set to run at the frequency of $1000 \mathrm{~Hz}$, hence the information is sent and received to/from the EFS500 flight simulator at every $20^{\text {th }}$ time step.

\subsection{Generic high aspect ratio wing aircraft model}

Figure 2 shows the generic HARW aircraft model used during the piloted simulation trials. It represents a medium-size T-tail configuration aircraft model with two engines mounted at the back of the fuselage.

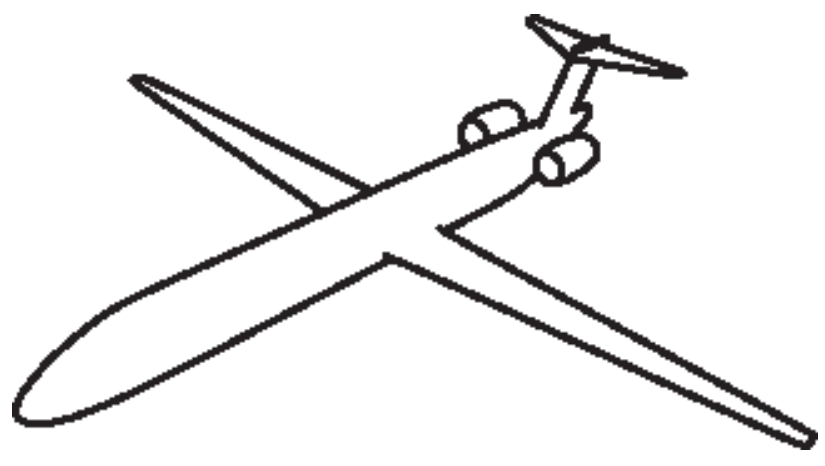

Figure 2. Generic HARW aircraft model 
The model was used as a test case of the highly deformable wing aircraft, which is referred to as a flexible aircraft in this article. The same model, but with an increased stiffness of the wing, was used as a test case of the relatively rigid wing aircraft, which is referred to as a rigid aircraft in this article. GA was simulated as a bare airframe, i.e. without FCS. Its mass was set to $79 \mathrm{t}$ and distributed in a way that the CG would be at $20 \%$ of its mean aerodynamic chord for the piloted simulation trials. However, the difference from other similar size aircraft lies within the wing parameters, i.e. its quarter chord sweep angle $\left(\lambda_{c / 4}\right)$ is $0.46^{\circ}$ and its AR is 17.7 . Thus, it qualifies as low-swept HARW aircraft. The flexibility of the fuselage, HTP and VTP was increased by setting the Young's modulus to infinity. Hence, these components of GA are considered as non-deformable throughout this article. The Young's modulus of the rigid wing was chosen to be $80 \mathrm{GPa}$, representing the usual values of aluminium alloys (Ashby, 2017), and $8 \mathrm{GPa}$ for the flexible wing to considerably increase deformations for the purpose of this research. Figure 3 shows resulting trim state wing deflections, when the aircraft was trimmed for the cruise flight at 10,000 $\mathrm{ft}$ and $204 \mathrm{kt}$. The same trim flight conditions were used as initial conditions to start each simulation.

\subsection{Flight test manoeuvres}

Several flight test manoeuvres were performed to identify the differences between rigid and flexible aircraft configurations. Firstly, the wing flexibility effect on the longitudinal HQs was assessed through the short period pitching oscillation (SPPO) mode and the phugoid mode tests. The typical period of the SPPO mode is 1-2 s (Stinton, 1996), which translates into the frequency of $0.5-1 \mathrm{~Hz}$. Figure 4 shows that this frequency range overlaps with the lowest modeshape frequencies of the flexible wing aircraft as well as human natural frequencies. Hence, it is essential for the SPPO mode be well damped. On the other hand, the phugoid mode is of much longer period, i.e. 40-100 s (Stinton, 1996). Then, the wing flexibility effect on the lateral/ directional HQs was assessed through the roll mode, the

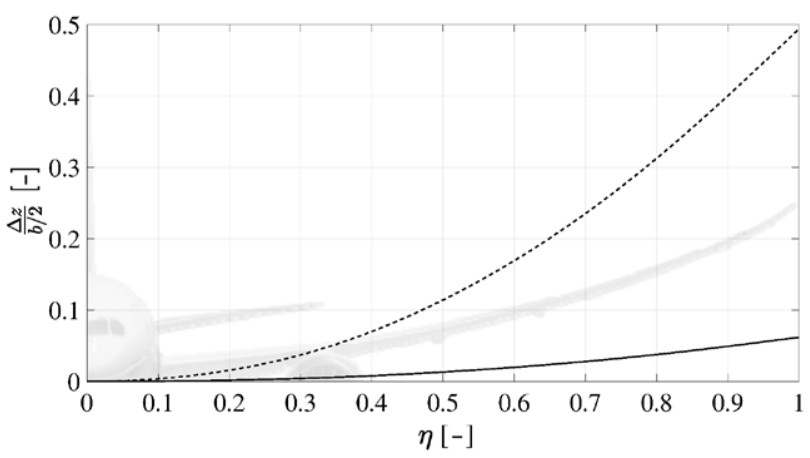

Figure 3. Trim state wing deformations for rigid (-) and flexible (- - ) wing aircraft. The shape of Boeing 787 aircraft in trimmed flight (Dodt, 2011) is given for illustration purpose. Here: $\Delta z$ - wingtip deflection in vertical direction under the load; $b$ - wing semi-span; $\eta$ - relative position along the wing

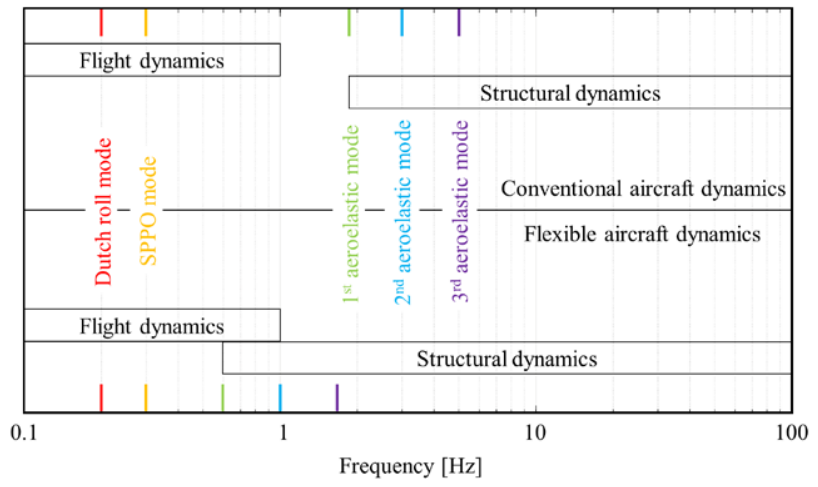

Figure 4. Frequencies of natural aircraft and aeroelastic modes for rigid and flexible wing aircraft

spiral mode and the Dutch roll mode tests. The roll mode is a non-oscillatory mode defined by the time constant $\tau_{\mathrm{r}}$, which typically should be less than a second. The spiral mode is also a non-oscillatory mode defined by the time constant $T_{2}$, which equals the time needed to double the amplitude of the bank angle $\Phi$ and is usually as large as 40 s. Being a long period mode it is of a little interest for HQs research as long as $T_{2}$ is more than $20 \mathrm{~s}$ or the period of the Dutch roll mode (Stinton, 1996). The Dutch roll mode is the only oscillatory lateral/directional mode (Ward \& Strganac, 2001) defined by the frequency, damping and the ratio of bank angle to sideslip angle $\Delta \Phi / \Delta \beta$. Low ratio, when sideslip dominates the mode, is preferred by pilots.

The aircraft response was also compared against the MIL-F-8785C requirements (Moorhouse \& Woodcock, 1981), for which the GA model qualified as class II (medium transport) aircraft and the initial flight test conditions corresponded to the category A flight phase $\left(\mathrm{V} \geq 1.2 \mathrm{~V}_{\mathrm{S}}\right.$ and 10,000 $\mathrm{ft}$ altitude).

Pilots used slalom task (Dussart et al., 2018) to test FQs of GA. The task was developed to assess an aircraftpilot couple's capability to perform real-life high-gain tasks. It aims to replicate an offset landing manoeuvre at a higher altitude to mitigate the deficiencies of SFFA, i.e. the absence of the ground effect and landing gear. Hence, the pilots had to fly through the spheres, as shown in Figure 5, which allowed assessment of whether a aircraft-pilot couple achieved desired (inner blue sphere) or adequate (outer orange sphere) performance.

The size of the spheres was defined according to usual runway dimensions, i.e. the diameter of $66 \mathrm{ft}$ for the smaller sphere represented the width of a usual touchdown zone, while the diameter of $262 \mathrm{ft}$ for the larger sphere represented the width of the widest runway at large aerodromes. For the distance considerations, it was assumed that the pilot's initial visual contact with the runway was at $200 \mathrm{ft}$ altitude, which represents the CAT I ILS minimum, and an aircraft was off the runway centreline by $2.5^{\circ}$, which is the full scale deflection of the ILS indicator. This led to the lateral offset of $430 \mathrm{ft}$ and the longitudinal separation of $7300 \mathrm{ft}$, also considering the fact that the aircraft was flown in a clean configuration at a higher velocity than it would experience when landing. 


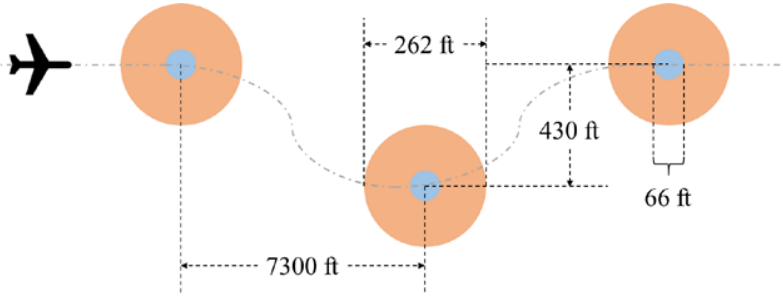

Figure 5. Definition of the slalom task

\section{Results and discussion}

The SPPO mode tests are indicated as SP in the following tables, the phugoid mode - $\mathrm{PH}$, the roll mode - RM, the spiral mode - SM, the Dutch roll mode - DR and the slalom task - SL. The rigid aircraft configuration is indicated as (R) and the flexible aircraft configuration is indicated as $(\mathrm{F})$.

\subsection{Longitudinal HQs}

Two sets of tests inducing the short period pitching oscillation and the phugoid modes were carried out to identify the differences between the longitudinal HQs of rigid and flexible wing aircraft. Although the phugoid mode manifests itself as a trimming problem and usually is of a little interest for HQs assessment, pilots continuously reported it as the dominant and intrusive longitudinal mode during piloted simulation trials presented in this article.

Both longitudinal modes were induced by the elevator deflection. The SPPO mode was induced by the doublet input (see Figure 6) and the phugoid mode was induced by the pulse input (see Figure 7). Response parameters of both modes are summarised in Table 1.

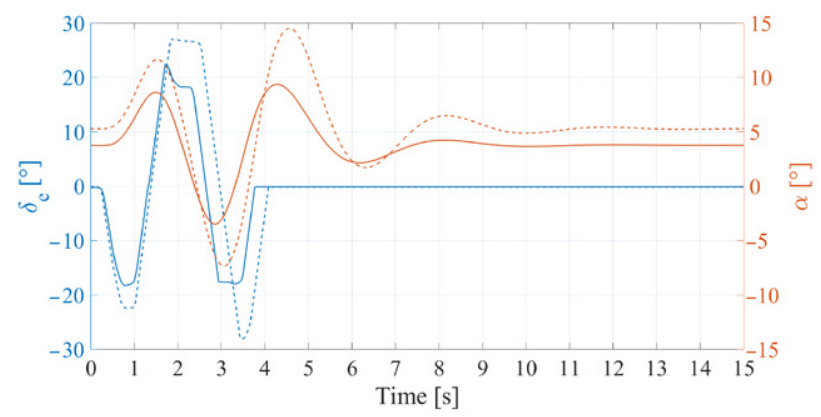

Figure 6. SPPO mode of rigid (-) and flexible (- - -) wing aircraft. Here: $\delta_{\mathrm{e}}$ - elevator deflection; $\alpha$ - angle of attack

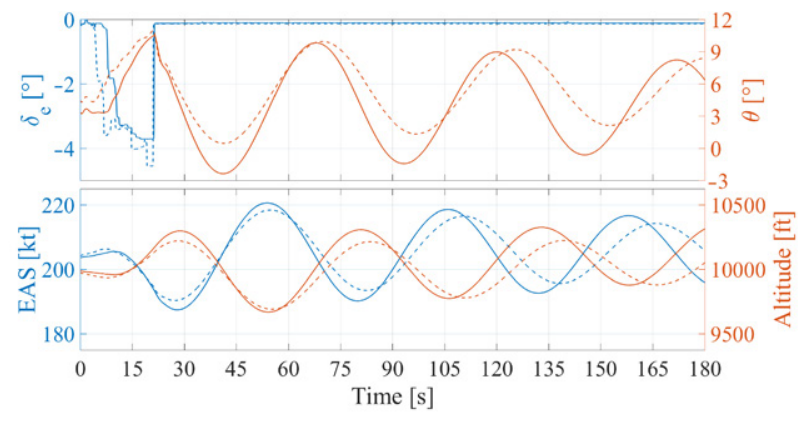

Figure 7. Phugoid mode of rigid (-) and flexible (- - ) wing aircraft. Here: $\delta_{\mathrm{e}}-$ elevator deflection; $\theta$ - pitch attitude; EAS - equivalent air speed
Table 1. SPPO and phugoid modes' parameters. Here: $T$ - period; $\omega_{d}$ - damped frequency; $\omega_{n}$ - natural frequency; $\zeta$ - damping ratio; $n_{\alpha}$ - acceleration sensitivity; CAP - Control Anticipation Parameter

\begin{tabular}{|c|c|c|c|c|c|}
\hline \multicolumn{2}{|c|}{ Test } & $\mathrm{SP}(\mathrm{R})$ & $\mathrm{SP}(\mathrm{F})$ & $\mathrm{PH}(\mathrm{R})$ & $\mathrm{PH}(\mathrm{F})$ \\
\hline \multicolumn{2}{|c|}{$T[s]$} & 3.9 & 3.6 & 52.1 & 55.5 \\
\hline \multicolumn{2}{|c|}{$\omega_{d}[\mathrm{~Hz}]$} & 0.26 & 0.28 & 0.02 & 0.02 \\
\hline \multirow[t]{2}{*}{$\omega_{n}$} & {$[\mathrm{~Hz}]$} & 0.28 & 0.29 & \multirow[t]{2}{*}{0.02} & \multirow[t]{2}{*}{0.02} \\
\hline & {$[\mathrm{rad} / \mathrm{s}]$} & 1.76 & 1.82 & & \\
\hline \multicolumn{2}{|c|}{$\zeta[-]$} & 0.38 & 0.32 & 0.02 & 0.03 \\
\hline \multicolumn{2}{|c|}{$n_{\alpha}[1 / \mathrm{rad}]$} & 4.58 & 8.59 & - & - \\
\hline \multicolumn{2}{|c|}{$C A P$} & 0.68 & 0.39 & - & - \\
\hline
\end{tabular}

The results show that the rigid aircraft exhibited higher damping of the SPPO mode. Although pilots assessed the SPPO mode of both rigid and flexible aircraft as heavily damped, the damping factor of the rigid aircraft met Level 1 requirement $\left(0.35 \leq \zeta_{\mathrm{sp}} \leq 1.30\right)$, while the damping factor of the flexible aircraft met Level 2 requirement $\left(0.25 \leq \zeta_{\text {sp }} \leq 2.00\right)$. Both rigid and flexible aircraft met Level 1 requirements with respect to the natural frequency $\omega_{n}$ and the acceleration sensitivity $n_{\alpha}$ of the SPPO mode. The Control Anticipation Parameter (CAP), which combines both $\omega_{n}$ and $n_{\alpha}$ and is expressed as (Cook, 2013):

$$
C A P=\frac{\omega_{n}^{2}}{n_{\alpha}}
$$

showed a reduced value for the flexible aircraft. Lower CAP value means that the flexible aircraft's response to a pilot's input is more sluggish and could potentially lead to an overshoot when a pilot makes corrective action to achieve targeted attitude. The values of $\omega_{n}, n_{\alpha}$ and CAP along with the limits for Levels 1, 2 and 3 are graphically represented in Figure 8.

The exhibited period of the SPPO mode was about twice longer when compared to the typical period length. The mode induction technique, i.e. the elevator doublet

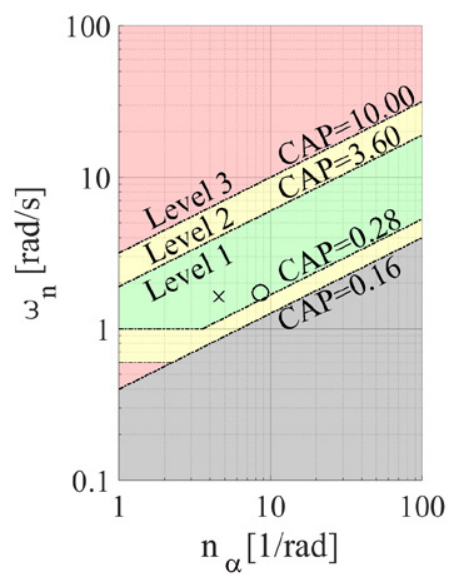

Figure 8. Mapping of rigid (x) and flexible (o) wing aircraft configurations CAP parameter against SPPO mode frequency requirements for flight phase category A (Moorhouse \& Woodcock, 1981) 
input, could be the reason for such difference. A brief trial to apply the frequency sweep technique, which covers a broad spectral range of frequencies, to measure the SPPO mode parameters resulted in the period of $T_{\mathrm{sp}}=1.6-1.8$ s. However, the pilots assessed both aircraft configurations as "qualitatively similar" when using the frequency sweep input.

CAP values were 0.68 for the rigid aircraft and 0.39 for the flexible aircraft. Figure 8 indicates both values within Level 1 requirements.

The phugoid mode, on the other hand, showed a different change of the damping factor, i.e. an increase for the flexible aircraft compared to the rigid aircraft. The damping factor of the mode was very low and met Level 2 requirement $\left(0 \leq \zeta_{\text {ph }} \leq 0.04\right)$. Low damping of the mode also reflected in the comments of the test pilots, where they noted many times and also in other tests that the flexible aircraft "started phugoiding without even making an input".

The tests of the longitudinal HQs showed negligible differences between rigid and flexible aircraft. Although the longitudinal HQs degraded for the flexible aircraft, no significant differences were recorded within the main aircraft response parameters. Hence, it was concluded that the two aircraft configurations are qualitatively similar in terms of longitudinal dynamics.

\subsection{Lateral/directional handling qualities}

The usual mode assessment techniques for all three lateral/directional modes are different. Hence, the roll mode was assessed by banking the aircraft between $\Phi= \pm 30^{\circ}$. The spiral mode was induced by banking the aircraft to $\Phi= \pm 15^{\circ}$, stabilising it at the set bank angle and then removing all control inputs to see further development of the bank angle. The Dutch roll mode was induced by a rudder doublet input.

The roll mode parameters of interest are presented in Table 2. Although the calculated roll mode time constant was $0.5-0.6 \mathrm{~s}$ and met Level 1 requirement $\left(\tau_{\mathrm{r}} \leq 1.4 \mathrm{~s}\right)$ for all test cases, the roll was not smooth as it could be anticipated from the $\tau_{\mathrm{r}}$ parameter. An investigation showed that another roll performance parameter $\tau_{+30^{\circ}}$, which defines the amount of time needed to roll an aircraft between two bank angles with opposite signs, was more than two times greater for the flexible aircraft. It was noticed by pilots that

Table 2. Roll mode parameters. Here: $\Phi$ - bank angle; $\delta_{\mathrm{a}}-$ aileron deflection; $\mathrm{p}$ - roll rate; $\tau_{\mathrm{r}}$ - roll mode time constant; $\tau_{ \pm 30^{\circ}}$ - time to roll between $\pm 30^{\circ}$ of bank angle

\begin{tabular}{|l|c|c|c|c|}
\hline \multicolumn{1}{|c|}{ Test } & $\mathrm{RM}(\mathrm{R})$ & $\mathrm{RM}(\mathrm{F})$ & $\mathrm{RM}(\mathrm{R})$ & $\mathrm{RM}(\mathrm{F})$ \\
\hline Direction & $\mathrm{L} \rightarrow \mathrm{R}$ & $\mathrm{L} \rightarrow \mathrm{R}$ & $\mathrm{R} \rightarrow \mathrm{L}$ & $\mathrm{R} \rightarrow \mathrm{L}$ \\
\hline$\Phi_{\text {datum }}$ & $-30.8^{\circ}$ & $-34.5^{\circ}$ & $32.2^{\circ}$ & $27.9^{\circ}$ \\
\hline$\delta_{\mathrm{a}}$ & $-25.0^{\circ}$ & $-25.0^{\circ}$ & $25.0^{\circ}$ & $25.0^{\circ}$ \\
\hline $\mathrm{p}_{\max }$ & $30.8^{\circ} / \mathrm{s}$ & $23.4^{\circ} / \mathrm{s}$ & $-32.8^{\circ} / \mathrm{s}$ & $-29.8^{\circ} / \mathrm{s}$ \\
\hline$\tau_{\mathrm{r}}$ & $0.5 \mathrm{~s}$ & $0.6 \mathrm{~s}$ & $0.5 \mathrm{~s}$ & $0.5 \mathrm{~s}$ \\
\hline$\tau_{ \pm 30^{\circ}}$ & $2.4 \mathrm{~s}$ & $5.0 \mathrm{~s}$ & $2.0 \mathrm{~s}$ & $5.5 \mathrm{~s}$ \\
\hline
\end{tabular}

the reason for this was wing ratcheting induced by the increased flexibility and, thus, the dihedral of the wing. Figure 9 clearly indicates the wing ratcheting phenomenon. Pilots expect that as long as the ailerons are deflected the aircraft should continue rolling. However, the flexible aircraft stops rolling after 3-3.5 s as indicated by roll rate $p$ in Figure 9. At this time frame the roll rate goes back to zero from its previous maximum value. Such a poor roll performance is an outcome of lost ailerons efficiency due to highly deformed wing. This phenomenon is highly undesirable in roll dynamics as it makes it a challenging task for pilots to anticipate the behaviour of an aircraft.

The spiral mode parameters are presented in Table 3. The rigid aircraft exhibited divergent spiral mode, which would be typically expected for an aircraft with a dihedral low-wing configuration. According to the $T_{2}$ parameter, the rigid aircraft met Level 1 requirement $\left(T_{2} \geq 12 \mathrm{~s}\right)$. However, the flexible aircraft exhibited neutral spiral mode stability, which is also shown in Figure 10. This stabilising effect is a clear evidence of the flexibility effect on the

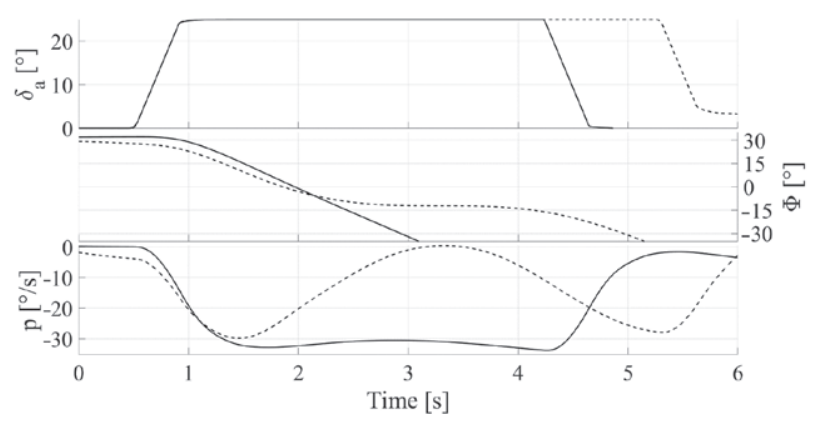

Figure 9. Roll performance of rigid (-) and flexible (- - -) wing aircraft. Here: $\delta_{\mathrm{a}}$ - aileron deflection; $\Phi$ - bank angle; $p$ - roll rate

Table 3. Spiral mode parameters. Here: $\mathrm{T}_{2}$ - time to double bank angle

\begin{tabular}{|l|l|l|}
\hline \multicolumn{1}{|c|}{ Test } & \multicolumn{1}{|c|}{$\mathrm{SM}(\mathrm{R})$} & \multicolumn{1}{c|}{$\mathrm{SM}(\mathrm{F})$} \\
\hline $\mathrm{T}_{2 \text { left }}$ & $32.8 \mathrm{~s}$ & $\infty$ \\
\hline $\mathrm{T}_{2 \text { right }}$ & $34.4 \mathrm{~s}$ & $\infty$ \\
\hline
\end{tabular}

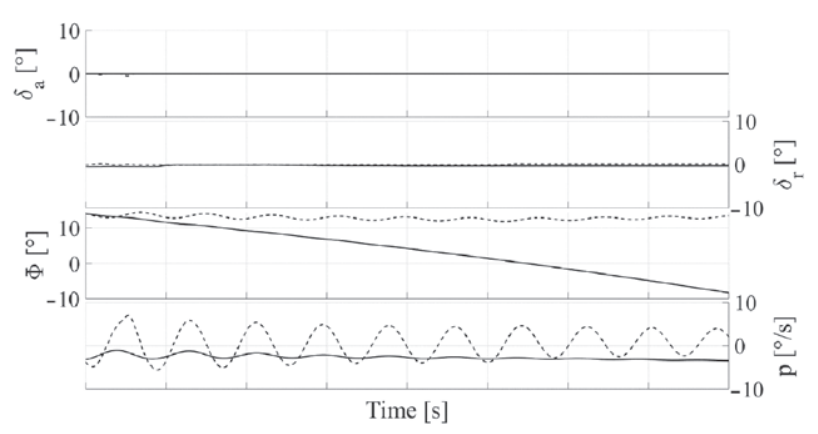

Figure 10. Spiral mode parameters of rigid $(-)$ and flexible $\left(--\right.$-) wing aircraft. Here: $\delta_{\mathrm{a}}-$ aileron deflection; $\delta_{\mathrm{r}}-$ rudder deflection; $\Phi$ - bank angle; p - roll rate 
dihedral, i.e. highly deformed wing transformed itself into laterally stabilising surface. Figure 11 shows the rollsideslip coupling oscillation, which indicates the flexible aircraft tendency for the Dutch roll. Figure 11 also shows greater increment of the roll rate rather than the sideslip angle oscillation magnitude for the flexible aircraft. This means a decrease of $C_{1_{\beta}}$ parameter. Nicolai and Carichner (2010) have shown that $C_{\mathrm{l}_{\beta}}$ parameter reduces with a reducing wing AR. For the current test case the effective wing AR of the flexible aircraft reduced due to a decrease of the effective wingspan due to an increased wing dihedral.

Table 4 presents the Dutch roll mode parameters. The mode was reported as an intrusive dynamic mode in the previous lateral/directional tests. As defined by the MILF-8785C requirements, the Dutch roll damping, its natural frequency and their product are the parameters to be assessed while testing aircraft characteristics. According to the mode's damping factor, both aircraft met Level 2 requirement $\left(0.02 \leq \zeta_{\mathrm{Dr}} \leq 0.19\right)$. Pilots' comments also noted the poorly damped mode. Both aircraft configurations met the natural frequency Level 1 requirement $\left(\omega_{\mathrm{n}_{\mathrm{Dr}}} \geq 0.06 \mathrm{~Hz}\right)$. Considering the product of both the damping factor and the natural frequency, the rigid aircraft met Level 2 requirement $\left(0.008 \mathrm{~Hz} \leq \zeta_{\mathrm{Dr}} \omega_{\mathrm{n}_{\mathrm{Dr}}} \leq 0.056 \mathrm{~Hz}\right)$ and the flexible aircraft met Level 3 requirement $\left(\zeta_{\mathrm{Dr}} \omega_{\mathrm{n}_{\mathrm{Dr}}} \geq 0 \mathrm{~Hz}\right)$. The $\Delta \Phi / \Delta \beta$ parameter in Table 4 reveals a significant change in the Dutch roll mode dynamics for the flexible aircraft. The horizontal ellipse motion of the mode for the rigid aircraft changed to the vertical ellipse motion of the mode for the flexible wing aircraft, as shown in Figure 12. As mentioned in the discussion of the spiral mode, this change happened due to

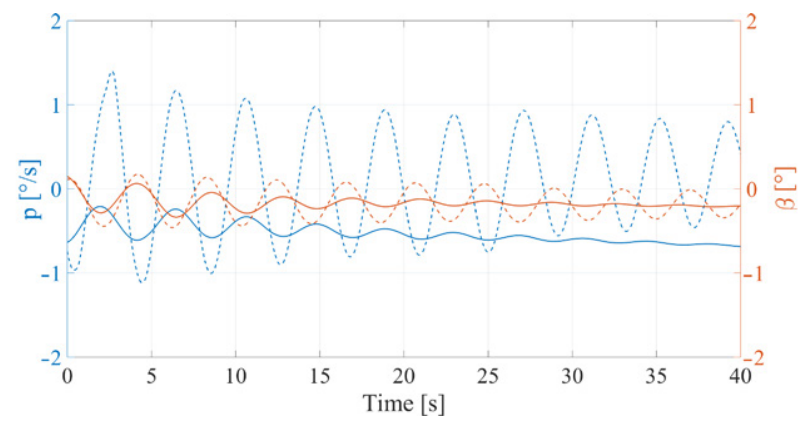

Figure 11. Coupling between the roll rate $\mathrm{p}$ and the sideslip $\beta$ during the spiral mode test; rigid (-) and flexible (- - -) wing aircraft. Here: $\mathrm{p}$ - roll rate; $\beta$ - sideslip angle

Table 4. Dutch roll mode parameters. Here: $T$ - period; $\omega_{\mathrm{d}}-$ damped frequency; $\omega_{\mathrm{n}}$ - natural frequency; $\zeta$ - damping ratio; $\Delta \Phi$ - bank angle change; $\Delta \beta$ - sideslip angle change

\begin{tabular}{|c|c|c|}
\hline Test & DR(R) & DR(F) \\
\hline$T_{\mathrm{Dr}}$ & $4.37 \mathrm{~s}$ & $4.22 \mathrm{~s}$ \\
\hline$\omega_{\mathrm{d}_{\mathrm{Dr}}}$ & $0.23 \mathrm{~Hz}$ & $0.24 \mathrm{~Hz}$ \\
\hline$\omega_{\mathrm{n}_{\mathrm{Dr}}}$ & $0.23 \mathrm{~Hz}$ & $0.24 \mathrm{~Hz}$ \\
\hline$\zeta_{\mathrm{Dr}}$ & 0.06 & 0.02 \\
\hline$\Delta \Phi / \Delta \beta$ & $2 / 3$ & $9 / 4$ \\
\hline
\end{tabular}

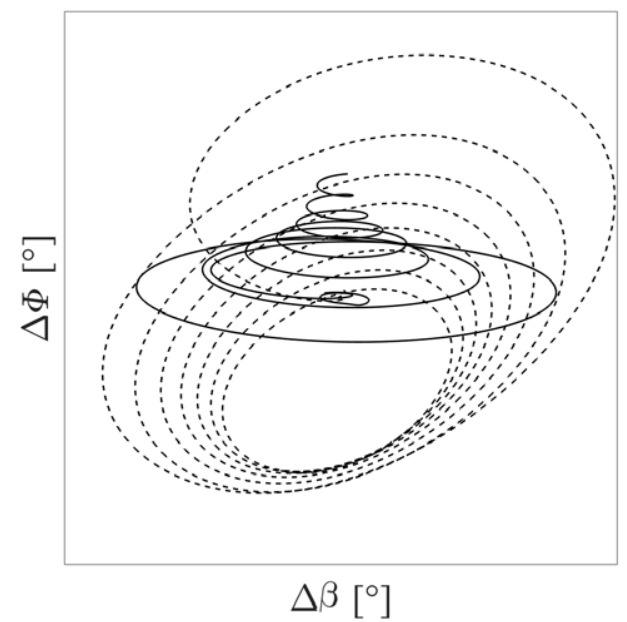

Figure 12. Dutch roll mode shape change from the horizontal ellipse of rigid (-) to the vertical ellipse of flexible (- - ) wing aircraft. Here: $\Delta \Phi$ - bank angle change; $\Delta \beta$ - sideslip angle change

an increased wing dihedral, which in turn decreased $\mathrm{C}_{\mathrm{l}_{\mathrm{B}}}$ parameter. This was a significant change and was reported by the test pilots as a serious deficiency of the flexible wing aircraft.

\subsection{Flying qualities}

The slalom task allowed comparison of FQs between the rigid and flexible aircraft. The pilots were asked to assess the longitudinal and lateral/directional FQs separately. The resulting CHR scores are provided in Table 5.

Overall, the longitudinal FQs and the rigid aircraft were evaluated better than the lateral/directional FQs and the flexible aircraft. However, as the previous tests showed negligible changes between the rigid and flexible aircraft longitudinal dynamics, the pilot's perception during the slalom task showed that these changes in dynamics were more significant. The rigid aircraft longitudinal FQs were assigned CHR-2, hence meeting desired tolerances, while the flexible aircraft longitudinal FQs were assigned CHR-4 meeting only adequate. This evaluation means that the flexible aircraft FQs are unsatisfactory without improvements, while the rigid wing aircraft FQs are satisfactory. The lateral/directional FQs, on the other hand, were assigned CHR-5 for the rigid aircraft assessing it as unsatisfactory. The flexible aircraft lateral/directional FQs were assigned CHR-7 not meeting even adequate tolerances. However, the aircraft was still controllable. Such an assessment of FQs does not surprise as: 1) the bare airframe without FCS was simulated, and 2) significant changes in the lateral/directional dynamics, indicated in the previous

Table 5. Cooper-Harper Rating scores during the slalom task

\begin{tabular}{|l|c|c|}
\hline \multicolumn{1}{|c|}{ Test } & SL(R) & SL(F) \\
\hline Longitudinal & 2 & 4 \\
\hline Lateral/directional & 5 & 7 \\
\hline
\end{tabular}




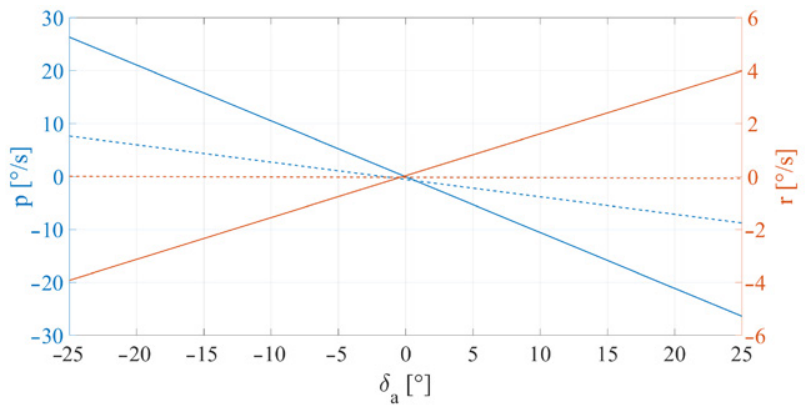

Figure 13. Adverse yaw during slalom tests; rigid (-) and flexible (- - ) wing aircraft. Here: $\delta_{\mathrm{a}}$ - aileron deflection; $\mathrm{p}$ roll rate; $r$ - yaw rate

tests and discussed above, may be undesirable for most pilots.

One of the pilots, who is currently operating commercial airliners, was asked to perform only the slalom task and no other tests. In this case the pilot had less structured preparation for the task and less exposure to the deficiencies of the aircraft. This acted as a surprise factor in the test. Firstly, he was asked to fly the rigid aircraft and then the flexible one. The pilot commented that such a significant change in aircraft dynamics due to an increased wing flexibility might cause significant issues for airline pilots.

The most important finding was that the slalom task successfully revealed most of the deficiencies of the aircraft. Adverse yaw, leading to the Dutch roll, and wing ratcheting, leading to the unpredictability of the roll dynamics were commented by test pilots. Figure 13 shows approximations of the roll rate $\mathrm{p}$ and the yaw rate $\mathrm{r}$ response to the aileron input during the slalom tests, as Durham (2013) states that for the adverse yaw the positive aileron deflection should result in a negative roll and a positive yaw. $p\left(\delta_{\mathrm{a}}\right)$ slopes are negative for both rigid and flexible cases. However, $r\left(\delta_{\mathrm{a}}\right)$ slopes are positive for the rigid cases, which evidence the adverse yaw phenomenon. According to one of the pilots the "combination of adverse yaw and Dutch roll" made the "bank angle control most challenging" in the rigid case. The other pilot concluded that the "nose was pitching up and down and yawing left and right - it was hard to know what input to make". The flexible aircraft exhibited less adverse yaw, but much of the wing rocking, which was experienced and reported by one of the pilots as "a lot of roll oscillations for any lateral control input".

\section{Conclusions}

Exposure of the differences between the rigid and flexible aircraft FQs and HQs was achieved through the piloted simulation trials of GA. SFFA was used to provide the flexible aircraft mathematical model and the cockpit environment.

The piloted simulation trials of the longitudinal modes indicated negligible differences between rigid and flexible aircraft. The main differences between two configurations were within the damping factor, i.e. the SPPO's damping reduced for the flexible aircraft, while the phugoid's damping increased for the flexible aircraft. Although changes in the damping factor of the two configurations were negligible, the HQs degraded from Level 1 to Level 2 with an increased wing flexibility.

Trials of the lateral/directional modes indicated significant differences between the rigid and flexible aircraft. Wing ratcheting was present during roll performance tests and doubled the time needed for the flexible wing aircraft to perform a $\pm 30^{\circ}$ roll reversal. The roll tests also indicated a problem of over reliance on the roll mode time constant $\tau_{\mathrm{r}}$ to define the roll dynamics as it did not properly reveal the lag in roll. The roll performance parameter $\tau_{ \pm 30^{\circ}}$ was suggested for the further assessments of the flexible aircraft. The spiral mode tests revealed neutral stability of the flexible aircraft compared to negative stability of the rigid aircraft. The Dutch roll mode tests revealed the reduction of the mode's damping for the flexible aircraft. It also showed significant change in the motion shape of the mode, i.e. the horizontal ellipse shape, which is typi$\mathrm{cal}$ for the most aeroplanes, changed to the vertical ellipse shape for the flexible aircraft. These changes in the lateral/ directional dynamics were mostly attributed to decreasing lateral static stability parameter $C_{\mathrm{l}_{\beta}}$ due to increasing wing flexibility and dihedral angle under load.

The slalom task showed degraded longitudinal and lateral/directional FQs for the flexible aircraft when compared to the rigid aircraft. Although the longitudinal FQs of the rigid aircraft were assessed as desired, the lateral/ directional FQs were assessed as unsatisfactory. The flexible aircraft exhibited a degradation of both the longitudinal FQs and the lateral/directional FQs. This degradation is well explained by the significant changes in its lateral/ directional dynamics and, thus, an increased workload for the pilots and the absence of a FCS.

Although the above mentioned piloted simulation trials were performed only by three test pilots they revealed many qualitative changes between the rigid and flexible wing aircraft dynamics. For further research it is recommended to increase the sample of pilots, to include both commercial and test pilots. Using a motion based flight simulator should also be considered for further research as it would allow higher fidelity assessment of flying and handling qualities.

\section{Acknowledgements}

The authors wish to thank Dr. Mohammad M. Lone from Cranfield University for the project management activities.

\section{Funding}

This work was supported by Airbus, Aerospace Technology Institute and Innovate UK through the Agile Wing Integration (AWI) project. 


\section{Disclosure statement}

The Authors declare that there is no conflict of interest.

\section{References}

Allerton, D. J. (2016). EFS500 - user guide. Aerosoft.

Andrews, S. P. (2011). Modelling and simulation of flexible aircraft: Handling qualities with active load control. Cranfield University.

Anonymous. (2017). Aviation benefits. Industry High Level Group. Ashby, M. F. (2017). Materials selection in mechanical design (5th ed.). Butterworth-Heinemann.

ATAG. (2016). Aviation: Benefits beyond borders. Air Transport Action Group.

Bradley, M. K., Droney, C. K., \& Allen, T. J. (2015). Subsonic Ultra Green Aircraft Research phase II: volume I - truss braced wing design exploration (NASA/CR-2015-218704/Volume I). NASA.

Cook, M. V. (2013). Flight dynamics principles: A linear systems approach to aircraft stability and control (3rd ed.). Butterworth-Heinemann.

Cooper, G. E., \& Harper, R. P. (1969). The use of pilot rating in the evaluation of aircraft handling qualities (NASA-TN-D-5153). NASA Ames Research Center.

Cooper, J. E., Lowenberg, M. H., Lone, M. M., Garry, K., Cooke, A. K., \& Coetzee, E. (2014). High Aspect Ratio Technology Enablers - HARTEn [Research proposal]. Airbus, University of Bristol, Cranfield University.

Damveld, H. J. (2009). A cybernetic approach to assess the longitudinal handling qualities of aeroelastic aircraft. Delft University of Technology.

DeLaurier, J. D. (1993). An aerodynamic model for flappingwing flight. The Aeronautical Journal, 97(964), 125-130. https://doi.org/10.1017/S0001924000026002

Dodt, T. (2011, September 15). Introducing the 787. ISASI 2011, Salt Lake City, UT.

Durham, W. (2013). Aircraft flight dynamics and control. Wiley.

Dussart, G. X., Portapas, V., Pontillo, A., \& Lone, M. M. (2018). Flight dynamic modelling and simulation of large flexible aircraft. In K. Volkov (Ed.), Flight physics - models, techniques and technologies (pp. 49-72). InTech. https://doi.org/10.5772/intechopen.71050

Dussart, G. X., Yusuf, S. Y., Portapas, V., Lopez Matos, G. E., \& Lone, M. M. (2018, January 8). Method to assess lateral handling qualities of aircraft with wingtip morphing. AIAA Atmospheric Flight Mechanics Conference, Kissimmee, FL. https://doi.org/10.2514/6.2018-1015

ESDU. (1990). Normal-force-curve and pitching-moment-curve slopes of forebody-cylinder combinations at zero angle of attack for Mach numbers up to 5 (ESDU 89008). ESDU International.

ESDU. (1992). Normal force and pitching moment of conical boattails (ESDU 87033). ESDU International.

ESDU. (2004). Normal force, pitching moment and side force of forebody-cylinder combinations for angles of attack up to 90 degrees and Mach numbers up to 5 (ESDU 89014). ESDU International.

ESDU. (2013). Aerodynamic centre of wing-fuselage-nacelle combinations: Effect of wing-pylon mounted nacelles (ESDU 77012). ESDU International.

Field, E. J., \& Rossitto, K. F. (1999, August 9). Approach and landing longitudinal flying qualities for large transports based on in-flight results. 24th Atmospheric Flight Mechanics Conference. Portland, OR. https://doi.org/10.2514/6.1999-4095

IATA. (2013). IATA technology roadmap. International Air Transport Association.
Kellari, D., Crawley, E. F., \& Cameron, B. G. (2018). Architectural decisions in commercial aircraft from the DC-3 to the 787. Journal of Aircraft, 55(2), 792-804.

https://doi.org/10.2514/1.C034130

Kim, D.-K., Lee, J.-S., Lee, J.-Y., \& Han, J.-H. (2008). An aeroelastic analysis of a flexible flapping wing using modified strip theory. Active and Passive Smart Structures and Integrated Systems 2008, 6928. https://doi.org/10.1117/12.776137

Leishman, J. G. (1988). Validation of approximate indicial aerodynamic functions for two-dimensional subsonic flow. Journal of Aircraft, 25(10), 914-922. https://doi.org/10.2514/3.45680

Leishman, J. G. (1993). Indicial lift approximations for two-dimensional subsonic flow as obtained from oscillatory measurements. Journal of Aircraft, 30(3), 340-351. https://doi.org/10.2514/3.46340

Leishman, J. G. (1994). Unsteady lift of a flapped airfoil by indicial concepts. Journal of Aircraft, 31(2), 288-297. https://doi.org/10.2514/3.46486

Lopez Matos, G. E., Portapas, V., Dussart, G. X., Lone, M. M., \& Coetzee, E. (2018, January 8). Pilot-in-the-loop flight simulation of flexible aircraft in Matlab/Simulink: Implementation and coding peculiarities. 2018 AIAA Modeling and Simulation Technologies Conference. Kissimmee, FL.

https://doi.org/10.2514/6.2018-0426

Moorhouse, D. J., \& Woodcock, R. J. (1981). Background information and user guide for MIL-F-8785C, military specification Flying qualities of piloted airplanes (AFWAL-TR-81-3109). USAF Wright Aeronautical Laboratories.

Nicolai, L. M., \& Carichner, G. (2010). Static stability and control. In Fundamentals of aircraft and airship design (pp. 575600). American Institute of Aeronautics and Astronautics. https://doi.org/10.2514/5.9781600867538.0575.0600

Noll, T. E., Brown, J. M., Perez-Davis, M. E., Ishmael, S. D., Tiffany, G. C., \& Gaier, M. (2004). Helios mishap investigation report. NASA.

Patil, M. J., \& Hodges, D. H. (2004). On the importance of aerodynamic and structural geometrical nonlinearities in aeroelastic behavior of high-aspect-ratio wings. Journal of Fluids and Structures, 19(7), 905-915. https://doi.org/10.1016/j.jfluidstructs.2004.04.012

Portapas, V., Cooke, A. K., \& Lone, M. M. (2016). Modelling framework for flight dynamics of flexible aircraft. Aviation, 20(4), 173-182. https://doi.org/10.3846/16487788.2016.1264719

Stinton, D. (1996). Flying qualities and flight testing of the aeroplane. Blackwell Science.

Theodorsen, T. (1949). General theory of aerodynamic instability and the mechanism of flutter (NACA-TR-496). NACA Langley Aeronautical Laboratory.

Tollefson, J. (2016). UN agency proposes greenhouse-gas standard for aircraft. Nature, 530(7590), 266-266. https://doi.org/10.1038/nature.2016.19336

Wagner, H. (1925). Uber die entstehung des dynamischen auftriebs von tragflun. Zeitschrift Fur Angewandte Mathematic and Mechanic, 5(1), 17-35. https://doi.org/10.1002/zamm.19250050103

Ward, D. T., \& Strganac, T. W. (2001). Introduction to flight test engineering (2nd ed.). Kendall/Hunt Publishing Company.

Waszak, M. R., Davidson, J. B., \& Schmidt, D. K. (1987). A simulation study of the flight dynamics of elastic aircraft (NASA CR-4102). NASA Langley Research Center.

Waszak, M. R., \& Schmidt, D. K. (1988). Flight dynamics of aeroelastic vehicles. Journal of Aircraft, 25(6), 563-571.

https://doi.org/10.2514/3.45623 